\title{
Daytime vs. Overnight Trading in Equity Index Futures Markets
}

\author{
Sandip Dutta (Corresponding author) \\ School of Business, Dept. of Economics and Finance \\ Southern Connecticut State University \\ 501 Crescent Street, New Haven, CT, 06515, U.S.A.
}

Tel: 1-203-392-7028 Fax: 1-203-392-5254 E-mail: duttas2@southernct.edu

\author{
Subhash C. Sharma \\ Dept. of Economics, Southern Illinois University Carbondale \\ Carbondale, IL, 62901, U.S.A. \\ E-mail: sharma@siu.edu
}

Received: May 6, 2012

Accepted: May 232012

Online Published: June 6, 2012

doi:10.5430/afr.v1n2p13

URL: http://dx.doi.org/10.5430/afr.v1n2p13

\begin{abstract}
In this study, we examine the information links between daytime and overnight trading sessions in the E-mini futures markets. Our analysis includes the overnight session which hitherto remains unexplored in the E-mini literature. Overall, the results suggest that, for the sample period considered, despite being 24-hour markets, the daytime and overnight sessions appear to be segmented and that the daytime session behaves like a separate daytime market. Also, the overnight session facilitates an efficient flow of information from one daytime session to the next, thereby mitigating the pricing errors in the process.
\end{abstract}

JEL Classification: G11, G12, G13, G14

Keywords: Information Shares, Futures Markets, E-mini

\section{Introduction}

The primary focus of this study is to examine the potential information links between daytime and overnight trading sessions in the E-mini futures markets (E-mini markets). The E-mini futures contracts (Note 1) trade exclusively on the fully automated GLOBEX trading platform at the Chicago Mercantile Exchange (CME) virtually 24-hours a day. We also examine if such a trading environment makes the E-mini markets any different from the ones that operate only during regular trading hours (henceforth will be referred to as "daytime markets"). One major contribution of this study lies in the fact that we include the overnight trading session on GLOBEX in our analysis, which -till dateremains unexplored in the literature, particularly after the introduction of E-minis in September 1997. We examine the E-mini NASDAQ-100 and E-mini S \& P 500 futures markets, and contrast the daytime and overnight trading sessions. In particular, we address the following four issues: (1) Are the daytime trading returns more volatile than the overnight returns? (2) Are the daytime E-mini trades more informative than the overnight trades? (3) Are the daytime and overnight trading sessions integrated or segmented? If these sessions are integrated, then in accordance with the results documented in extant literature, the overnight trades should mitigate the pressure on trading volume at the beginning of, and at the end of the daytime trading sessions. (4) Do the overnight trades help mitigate the pricing errors at the beginning of the daytime trading sessions? The answers to these questions can provide insights into the influence of information arrival and processing of the same on market efficiency and integration. Further, a better understanding of the mechanics of both daytime and overnight trading will help the CME in improving the governance of automated trading on GLOBEX. The above issues have never been examined in a scenario where the market under consideration is open for virtually 24-hours. Results on similar issues documented in the literature and pertaining to daytime markets in general, motivate us to re-examine these issues in a truly 24-hour setting.

We begin by partitioning the trading period into daytime (8:30AM to 3:15PM, Chicago time, Note 2) and overnight (3:30PM to 8:29:59AM, the next day) sessions. First, we find that daytime trading returns are significantly more volatile as compared to their overnight counterparts. What is striking here is that despite the E-mini markets being 
24-hour markets, this result is not in contrast with those obtained in earlier studies on daytime markets. These studies show that daytime trading returns are significantly more volatile as compared to the non-trading overnight returns. This apparent similarity with daytime markets motivates us to explore the reasons behind this phenomenon.

Second, assuming that trade price volatility is directly related to the information flow as suggested by Ross (1989), it may be argued that significantly more information is revealed during the daytime trading sessions. Results from the Hasbrouck (1995) information share model confirm that the daytime trades are indeed more informative as compared to their overnight counterparts, thereby providing some preliminary evidence in favor of market segmentation.

Kurov et al. (2004) argue that exchange locals (trading E-minis) use their proximity to large buy/sell order flow information arriving into the pits and take strategically accurate positions on GLOBEX. In other words, they transfer a substantial chunk of those large floor orders to the GLOBEX platform in order to take advantage of its superior order execution speed, while the information which initiated those large floor orders is still fresh and may be acted upon. Kurov (2008) show that trades initiated by exchange-locals account for more than $60 \%$ of price discovery during the trading day. Tu and Wang (2007) note that E-minis improve the information flow in futures markets. Chung (2010) find that pricing errors are smaller in E-mini markets as compared to floor-traded markets and conclude that electronic trading has special attractions for informed traders. Massimb and Phelps (1994) report that trading on GLOBEX is quite expensive unless trades occur in large volumes, thereby lowering the average total cost/unit of trade. Kurov et al. (2004), further argue that the E-mini traders collectively raise the trading volume on GLOBEX around the time when large orders hit the floor, and they cite this as the main reason for the exponential growth in daytime trading volume on GLOBEX, despite the cost disadvantage as pointed out by Massimb and Phelps (1994). Hence, if the locals trade mostly around large floor orders in order to avoid the high cost of trading on GLOBEX, then there should not be much of an incentive for them to trade during the overnight session when the floor is closed. The E-mini traders should therefore behave as if they are operating in a daytime market, and this behavior should be reflected in the trading volume from both the sessions. This, in turn would indicate if the two sessions are integrated or segmented. Moreover, considering the fact that this practice of trading around large floor orders and the reasons behind the same -as discussed above- are public news, it should also deter foreign traders from trading aggressively during the overnight session. These arguments and the apparent similarity of E-mini markets with the daytime markets in general -as suggested by our initial results reported earlier- motivate us to contrast the daytime and overnight trading volumes in order to determine if the daytime and overnight sessions in the E-mini markets collectively behave like a 24-hour market or like two separate markets.

We find that for the sample period considered, the daytime trading volumes are significantly higher as compared to their overnight counterparts and that the trading volumes from both sessions depict separate U-shapes, as found in quite a few earlier studies on daytime markets. Based on these observations we conclude that the daytime and overnight sessions are segmented in accordance with the arguments in Werner and Kleidon (1996). Further, these results also confirm that the daytime session behaves like a separate daytime market, which in turn explains the higher variance of daytime trading returns - a typical result for daytime markets in general where overnight sessions do not exist- and also the higher information share associated with the daytime session. This finding also explains the U-shaped volume pattern for the daytime session, thereby indicating that the existence of an overnight session does not mitigate the pressure on trading volume at the beginning of, and at the end of the daytime session. The U-shaped volume pattern for the daytime session is also in sharp contrast to the arguments in Brock and Kleidon (1992), which is not surprising given the fact that the daytime session behaves like a separate daytime market. This apparent paradox may also be explained if we view the above results in light of the key finding documented in Massimb and Phelps (1994) and Kurov et al. (2004), as discussed above; given the current trading environment at the CME, there is not much of an incentive for the E-mini traders to trade during the overnight session, when the "floor is closed".

Finally, Grossman et al. (1980) show that the competitive equilibrium which binds the different fragments of the notion of efficiency together, breaks down due to lack of trade. This result and the substantially lower trading volume associated with the overnight sessions therefore motivate us to examine the efficiency aspect of the overnight trading session by particularly focusing on pricing errors (i.e., the variance of trading returns at the beginning of the daytime session). The central argument here is that the overnight session has the potential to process and efficiently transfer the information relayed from the daytime session, and give the E-mini traders a benchmark price to go by at the beginning of the daytime session, which begins the next day. Hence, in accordance with the arguments in Amihud and Mendelson (1991), Dhillon et al. (1997) and Tse (1999), the variance of "24-hr-8:30AM-to- 8:30AM" returns (i.e., the pricing errors for the daytime session which is not preceded by a long non-trading overnight period) should not be significantly different from that for the "24-hr-3:15PM-to-3:15PM" returns. However, the results from Grossman et al. (1980) cast a doubt if this will hold true for the E-mini markets with such low trading volume for the 
overnight sessions. We find that for the sample period considered, the overnight session, despite its low trading volume, acts as a medium through which information is efficiently transferred from one daytime session to the next, thereby mitigating the pricing errors at the beginning of each daytime session. This result is in sharp contrast to the findings documented in previous studies on daytime markets where researchers have found that significantly higher pricing errors vis-à-vis close-to-close returns are a characteristic feature of such markets (e.g., Amihud and Mendelson 1987; Stoll and Whaley 1990).

In what follows next, we bridge the literature on daytime and overnight trading and also discuss our research objectives, followed by a description of the data and a discussion on the methodology and results. Finally, we present the conclusions of this study.

\section{From Daytime Trading to Round-the-Clock Trading}

Coppejans and Domowitz (1999) examine the mechanics of the GLOBEX trading platform before the introduction of E-minis in 1997. GLOBEX was just an after-hours trading venue for the regular futures contracts during the sample period (7/1/94 thru 9/1/94) that they consider. The introduction of E-minis in September 1997 has dramatically changed the scenario, and these markets are now the most liquid markets in CME's history. These changes therefore warrant another look at the daytime and overnight trading sessions.

Oldfield and Rogalaski (1980), French and Roll (1986), Barclay et al. (1990) and Tse (1999), compare the variance of daytime and overnight trading returns and find that daytime trading returns are significantly more volatile as compared to their non-trading overnight counterparts. These are however studies on daytime markets. These results motivate us to re-examine this issue in the context of E-mini futures markets, i.e., in a 24-hour setting.

Ross (1989) argues that if the volatility of returns is caused by the release of public information, then volatilities during trading and non-trading hours are primarily related to the flow of information in general, rather than private information and noise trading as suggested by Oldfield and Rogalaski (1980), French and Roll (1986) and Barclay et al. (1990). Tse (1999) examines the Japanese Government Bond Futures contracts traded at the Tokyo Stock Exchange (TSE) and at the London International Financial Futures and Options Exchange (LIFFE) and argues likewise. Therefore, in the E-mini futures markets, if the daytime trading returns are significantly more volatile as compared to their overnight counterparts, then one possible explanation could be that significantly more information is revealed during the daytime trading sessions, and it would also provide some preliminary evidence in favor of market segmentation. Results from the previous studies on daytime markets therefore motivate us to examine these notions in the context of E-mini futures markets.

The previous studies on E-minis limit the analysis to regular trading hours only. Hasbrouck (2003), Kurov et al. (2004) and Ates et al. (2005) study the price discovery aspects of E-minis. They find that E-minis lead the price discovery process. Kurov et al. (2004) further argue that the exchange locals trading E-minis take strategically accurate positions on GLOBEX around the time when large (buy/sell) orders hit the floor. They also observe that trades between exchange locals and off-exchange customers account for the largest proportion of trading volume for the two E-mini contracts considered here. One major finding of their study is that the proximity of the exchange locals to the trading floor, coupled with the superior order execution speed on GLOBEX, result in the price discovery dominance of E-minis. Massimb and Phelps (1994) argue that exchange locals generally prefer the floor over GLOBEX due to the fact that trading on GLOBEX is quite expensive. Transaction costs are higher on GLOBEX and commissions are charged on a per contract basis. However, they further observe that if for some reason the aggregate trading volume increases on GLOBEX, then the overall transaction cost declines vis-à-vis the same for floor trades, thereby making it economical to trade on GLOBEX. Kurov et al. (2004), conclude that when the information regarding a large buy/sell order hits the floor and the locals need to act fast on that information to make a profit, the GLOBEX platform, with its superior order execution speed, provides them with an opportunity to execute a substantial number of orders within a short time window while the information -which initiated those large floor orders in the first place - is still fresh. At that time, a substantial chunk of floor orders gets transferred to GLOBEX, which boosts the trading volume and makes it economical for the locals to trade on GLOBEX. Kurov et al. (2004) cite this as the main reason for the exponential growth in daytime trading volume on GLOBEX, despite the cost disadvantage as pointed out by Massimb and Phelps (1994). Kurov (2008) further report that trades initiated by exchange-locals account for more than $60 \%$ of price discovery during the trading day. Finally, GLOBEX remains closed from 3:15PM thru 3:30PM and from 4:30PM thru 5:00PM. These being central times, it does not leave a time window wide enough to fit the E-mini trader's scheme of things, particularly to make use of information released after hours. 3:15PM in Chicago means 4:15PM in New York, which is 15 minutes past the closing time for the 
markets in the east coast. The after hours markets open at 4:00PM (ET) and close at 6:30PM (ET). In Chicago, the GLOBEX remains closed for 45 minutes during that time window.

It follows from the above discussion that for the E-mini market participants (mostly exchange locals who also maintain trading desks at the CME floor), there should not be much of an incentive for them to continue with E-mini trading once the CME floor closes for the day. Moreover, the fact that the practice of trading around large floor orders -due to reasons discussed above- is public news, it should also discourage the foreign traders from trading aggressively during the overnight session. An examination of the daytime and overnight trading volume should therefore reveal if these two sessions collectively behave like a 24-hour market or like two separate markets. It is in this backdrop that we proceed to contrast the trading volumes from both daytime and overnight sessions, and examine if these two sessions are integrated or segmented.

It is quite well known that intra-day volume patterns in stock markets are U-shaped (Wood et al., 1985; Harris, 1986; Werner \& Kleidon,1996; Barclay et al., 2003), i.e., heavy trading at market open and close, and relatively thin trading in the middle. Admati and Pfleiderer (1988) suggest that such volume patterns arise as a result of contrasting trading strategies on the part of informed and uninformed traders (i.e., liquidity traders). In a more recent study, Barclay et al. (2003) also provide empirical support for this line of reasoning. Brock and Kleidon (1992), however, argue that heavy trading at market open and close stem from the presence of a long overnight period during which traders cannot trade. In the case of E-mini markets, however, trading may continue overnight on GLOBEX. Hence, in accordance with the arguments in Brock and Kleidon (1992), the overnight screen-trades should mitigate the pressure on trading volume at the beginning of, and at the end of the daytime trading sessions. We examine this notion by analyzing the volume patterns in both the E-mini S\&P 500 and E-mini NASDAQ-100 futures markets. Finally, Werner and Kleidon (1996) argue that if there are two markets A (assume this market to be the overnight trading session) and B (assume this to be the daytime trading session), and if Market A's close (open) coincides with the opening (closing) of Market B, then the traders should be indifferent between trading at Market A's close (open) and at Market B's open (close), if these two markets are integrated. They further argue that if markets A and B are integrated, then their individual volume patterns should merge to form a single U-shaped curve. We examine this notion by analyzing the trading volumes from the daytime and overnight sessions.

Amihud and Mendelson (1987) examine the effects of two contrasting trading mechanisms -the periodic clearing house mechanism and the continuous dealership mechanism (Note 3)- on the behavior of returns on active New York Stock Exchange (NYSE) stocks. Comparing the behavior of open-to-open and close-to-close returns, they conclude that this difference in trading mechanism significantly affects the behavior of stock returns, and hence, the variance of open-to-open returns is significantly higher as compared to the same for close-to close returns. Stoll and Whaley (1990), however, argue that since the market specialist determines the opening price at the NYSE -thereby ending the overnight period with no trading activity- and allows the market makers to begin regular trading activity by posting their quotes, (s)he needs to be compensated for the service rendered to the market participants. The higher volatility of open-to-open returns as compared to the same for its close-to-close counterpart -i.e., the noise- may therefore be regarded as the specialist's compensation. Amihud and Mendelson (1991) further examine this issue using the data from TSE (Note 4). They find that for the afternoon session, which is not preceded by a long non-trading period, the open-to-open returns exhibit the same volatility pattern as compared to their close-to-close counterparts. They conclude that the prime reason for the higher volatility of returns at market open -i.e., the pricing errors at market open- is the existence of a long non-trading period.

In tune with the findings in Amihud and Mendelson (1991), Dhillon et al. (1997) examine identical gold futures contracts traded at the Commodity Exchange of New York (COMEX) and at the Tokyo Commodity Exchange (TOCOM). They examine open-to-open and close-to-close returns for these two markets and find that COMEX open-to- open return variance is $12 \%$ greater than its close-to-close counterpart, and the same is just $5 \%$ for TOCOM. Supporting the arguments of Amihud and Mendelson (1991), Dhillon et al. (1997) conclude that it is due to the efficient flow of information from the open market (COMEX) to the closed market (TOCOM), that the TOCOM open-to-open return variance is only $5 \%$ greater as compared to its close-to-close counterpart. Similarly, the higher (12\%) open-to-open return variance for COMEX may be explained by the fact that the information revealed during the TOCOM trading period is not efficiently transferred to the closed market COMEX. Tse (1999) argues likewise. Finally, Grossman et al. (1980) argue that the non-existence of competitive equilibrium in financial markets may be thought of as a breakdown of competitive markets due to lack of trade. In view of the fact that the overnight trading volume might be significantly low as compared to its daytime counterpart, we are motivated to examine if the overnight trading session is capable of processing and efficiently transferring information from one daytime trading session to the next and mitigating the pricing errors in the process. In other words, the overnight session has the 
potential to process and efficiently transfer the information relayed from the daytime session, and give the E-mini traders a benchmark price to go by at the beginning of the daytime session, which begins the next day. Hence, it is quite logical to expect that the variance of "24-hr-8:30AM-to- 8:30AM" returns should not be significantly different from that for the "24-hr-3:15PM-to-3:15PM" (Note 5) returns. However, in view of the Grossman et al. (1980) results, we examine if this notion will hold true for E-mini markets, despite the low trading volume associated with the overnight sessions.

\section{Data}

For this study, we employ the transactions data for two major equity index futures contracts traded on GLOBEX: (i) E-mini S\&P 500 and (ii) E-mini NASDAQ-100 (Note 6). These data are obtained from the Commodity Futures Trading Commission (CFTC). Our sample period extends from September 1, 2004 to August, 31, 2005 (259 trading days). Our objective was to obtain data for a period free from the influences of the recent credit crisis. The credit crisis, its associated dynamics and influences on futures market are too broad to address in one study. Furthermore, data availability issues limited us to this sample period only. We only consider the nearby futures contracts for the analysis. The E-mini S\&P 500 was launched on September 9, 1997 and the E-mini NASDAQ-100 was introduced on June 21, 1999. Both these contracts trade exclusively on GLOBEX 24-hours a day; except from 3:15PM to 3:30PM, and from 4:30PM to 5:00PM. The raw data set obtained from CFTC contains six variables; for each trade transaction we have the ticker symbol ( $\mathrm{ES}=\mathrm{S} \& \mathrm{P} 500 / \mathrm{NQ}=$ NASDAQ-100), contract maturity date, order execution date, order execution time, number of contracts traded and the contract price. The raw data set documents all trades that occur at each point in time. For example, if 20 different E-mini S\&P 500 transactions occur at 8:45:36 AM, the raw data set documents each such transaction. If more than one transaction occur at any point in time, then in accordance with the earlier studies on E-minis, only the last observation is considered.

Some basic summary statistics for the average intra-day trading volumes are presented in Table 1 below and a comprehensive illustration is presented in Figure 1.

Insert Table 1 here

\section{Methodology and Empirical Results}

\subsection{Daytime and Overnight Trading Returns}

To examine whether daytime trading returns are more volatile as compared to their overnight counterparts, the trade prices reported at 8:30AM and 3:15PM are used to compute the returns for the daytime trading sessions, while the trade prices reported at 3:15PM and 8:30AM, the next day, are used to compute the returns for the overnight sessions. An $F$-test is then employed to examine whether the variance of daytime trading returns is significantly higher as compared to its overnight counterpart. The summary statistics and results presented in Table 2 below, confirm that for the sample period considered, the daytime trading returns are significantly more volatile as compared to their overnight counterparts in both the E-mini S\&P 500 and E-mini NASDAQ-100 futures markets. Despite the fact that the E-mini futures markets are open for virtually 24-hours, these results are consistent with those obtained in quite a few earlier studies on U.S. and Japanese stock markets (e.g., Oldfield and Rogalaski 1980; French and Roll 1986; Barclay et al. 1990; Tse 1999) which operate only during regular trading hours (i.e., daytime markets in general). Going by the assumption that volatility of returns is caused by the release of public information (Ross 1989), this finding therefore poses the question: Is the daytime trading session more informative compared to its overnight counterpart? If that is indeed the case, then it might explain the higher volatility of daytime trading returns reported here.

Insert Table 2 here

\subsection{Are the Daytime Trades more Informative?}

First we separate the daytime and overnight trades. The overnight session being longer in duration as compared to its daytime counterpart, in order to obtain trade price time series of approximately the same length, the daytime trade series is spaced at 5-minute intervals and the overnight series at 12 -minute intervals respectively. These two price series (Note 7) are then used as inputs for the VECM based Hasbrouck (1995) information share model to obtain the information shares.

Since the same contract is traded during the daytime and overnight sessions, it is quite logical to expect that the daytime and overnight futures prices should share a common random-walk component and move together in the long run. These two price series should therefore form a cointegrated system, and further, based on the Granger 
representation theorem (Engle and Granger 1987), the price changes may be represented by a vector error correction model (VECM) as follows:

$$
\Delta p_{t}=\Pi z_{t-1}+\sum_{i=1}^{k} \Gamma_{i} \Delta p_{t-i}+\varepsilon_{t}
$$

where $z_{t-1}=p_{1, t-1}-p_{2, t-1}$ is the error correction term (Note 8), $\Delta$ is the first difference operator, $p_{t}$ is a ( $\left.2 \times 1\right)$ vector of cointegrated prices, $\Gamma_{i}$ is a ( $\left.2 \times 2\right)$ matrix of autoregressive coefficients, $k$ is the number of lags. $\Pi=\alpha \beta^{\prime}$ is a (2X 2) matrix, $\alpha$ is (2X 1) adjustment parameter vector, $\beta^{\prime}$ is a (2X 1) cointegrating vector, which in accordance with quite a few earlier studies is restricted to $(1,-1)^{\prime} . \varepsilon_{t}$ is a $(2 \mathrm{X} 1)$ error vector of serially uncorrelated residuals with covariance matrix $\boldsymbol{\Omega}$.

The Hasbrouck (1995) information share model is then used to obtain the information shares. The Hasbrouck (1995) approach uses the VECM (1) (Note 9) as its basis. He demonstrates how equation (1) may be represented in a vector moving average form (VMA):

$$
p_{t}=\psi\left(\sum_{s=1}^{t} \varepsilon_{s}\right) \ell+\Psi *(L) \varepsilon_{t}
$$

where $\ell=(1,1)^{\prime}$ is a column vector, $\psi=\left(\psi_{1} \psi_{2}\right)$ is a row vector and $\Psi *(L)$ is a matrix polynomial in the lag operator. His argument is that in cointegrated markets there is an implicit efficient price which is common to all markets, and the sources of variation in this efficient price are attributed to the different markets. In this framework, Hasbrouck (1995) defines information share as the proportion of the efficient price innovation variance that can be attributed to the respective markets. Accordingly, he shows that the increment $\psi \varepsilon_{t}$ in (2) is the common factor innovation and the component of the price change that is permanently impounded into the security price, and is presumably due to new information. Finally, he decomposes the variance of the common factor innovations as $\operatorname{var}\left(\psi \varepsilon_{t}\right)=\psi \Omega \psi^{\prime}$, and defines the information share of a market as the proportion of $\operatorname{var}\left(\psi \varepsilon_{t}\right)$ that is attributable to the innovations in that market. If $\boldsymbol{\Omega}$ is diagonal (i.e., if the market innovations are uncorrelated across markets), the information share of market $j$ is given by:

$$
I S_{j}=\frac{\psi_{j}^{2} \sigma_{j}^{2}}{\psi \Omega \psi^{\prime}},
$$

where $\psi_{j}$ is the $j$-th element of $\psi$. If the price innovations are correlated across markets, then it is impossible to obtain the information shares using (3). In that case the results depend upon the ordering of the variables in the Cholesky decomposition of $\boldsymbol{\Omega}$, and Hasbrouck's model produces estimates of upper and lower bounds of the information shares. For the purpose of this paper, we use the approach suggested by Baillie et al. (2002), and calculate the information shares directly from VECM(1) without obtaining VMA (2) (Note 10). The Hasbrouck (1995) information share model has been used in quite a significant number of studies in the past (Tse, 1999; Hasbrouck, 2003; Kurov et al., 2004; Ates et al., 2005, to note a few). These studies vouch for the relevance of the information share model in this study. The information share estimates for the daytime and overnight trading sessions are reported in Table 3 below.

\section{Insert Table 3 here}

The information share estimates clearly indicate that for the sample period considered, the daytime trades in the E-mini S\&P 500 and E-mini NASDAQ-100 futures markets are indeed more informative as compared to their overnight counterparts, thereby suggesting that significantly more information is revealed during the daytime sessions and that the daytime and overnight sessions are probably segmented. The mean estimated information shares for the daytime and overnight trades are $66.92 \%$ and $33.08 \%$ for E-mini S\&P 500 and $99.38 \%$ and $0.61 \%$ for E-mini NASDAQ-100 Futures respectively. These results are consistent with the arguments and results documented in Ross (1989) and in Tse (1999).

\subsection{Market Segmentation}

Our objective here is twofold; (i) to see if the daytime and overnight sessions are integrated or segmented (ii) to see if the overnight session helps in mitigating the pressure on trading volume at the beginning of, and at the end of the daytime trading session. We partition each 24-hour period into 1-hour intervals. The first interval starts at 12:00AM. To maintain continuity, we also include the 30- minute interval from 8:00AM to 8:29:59AM as part of the overnight 
trading session. The trading volumes corresponding to each interval are then added over the entire sample period and subsequently divided by the number of sample trading days to compute the average intra-day trading volumes for the sample period. The average volume patterns for the E-mini S\&P 500 and E-mini NASDAQ-100 Futures -for the entire sample period- are illustrated in Figures 1 (a) and 1 (b).

\section{Insert Figure 1(a) here \\ Insert Figure 1(b) here}

Consistent with quite a few earlier studies where trading activities do not occur round-the-clock (Wood et al., 1985; Harris, 1986; Werner \& Kleidon, 1996; Barclay et al., 2003), both figures depict U-shaped volume patterns for the daytime trading sessions. These results are consistent with the microstructure model discussed in Admati and Pfleiderer (1988). The arguments in Brock and Kleidon (1992) however fail to explain the U-shaped volume patterns for the daytime trading sessions. Since GLOBEX operates virtually 24-hours a day, the traders have the option to trade before 8:30AM in the morning (i.e., before the daytime trading session begins), and anytime after 3:15PM in the evening (i.e., after the daytime session ends). Hence, according to Brock and Kleidon (1992), we should not observe such clear U-shaped volume patterns for the daytime trading sessions. The trading volumes for the overnight sessions are extremely low as compared to the same for the daytime sessions. Further, we also observe separate U-shapes for the daytime and overnight sessions, which indicate that these sessions are segmented in accordance with the arguments in Werner and Kleidon (1996). What makes our results in FIGURE I even more striking is that we observe clear evidence of market segmentation despite the fact that we are examining a scenario where the same asset -an E-mini futures contract- is traded in both in the daytime and overnight sessions.

Our results provide empirical support for the arguments documented in Massimb and Phelps (1994) and Kurov et al. (2004), and are in conformity with the notion that we phrased earlier; given the current trading environment at the CME, there is really not much of an incentive for the E-mini traders to trade overnight, when the "floor is closed". This is probably the prime reason why the daytime and overnight sessions are segmented and that the overnight session does not mitigate the pressure on trading volume at the beginning of, and towards the end of the daytime session, which is typical for daytime markets in general. The E-mini markets are therefore not exactly 24-hour markets to the true sense of the word. It is therefore not surprising to observe that the daytime trading returns are significantly more volatile, and that the daytime trades are more informative as compared to their overnight counterparts. Also, the fact that the daytime session seems to operate as a separate daytime market, explains the sharp contrast with the arguments in Brock and Kleidon (1992).

\subsection{Overnight Trades and Pricing Errors}

In order to examine whether overnight trades help mitigate the pricing errors at the beginning of the daytime trading sessions, we use the $8: 30 \mathrm{AM}$ and $3: 15 \mathrm{PM}$ prices to compute the "24-hr-8:30AM-to-8:30AM" and "24-hr-3:15PM-to-3:15PM" returns. Table 4 reports the summary statistics and comparisons of "24-hr-8:30AM-to-8:30AM" and "24-hr-3:15PM-to-3:15PM" return variances in the E-mini S\&P 500 and E-mini NASDAQ-100 futures markets.

Insert Table 4 here

The $F$-statistics (1.06 for E-mini NASDAQ-100 and 1.16 for E-mini S\&P 500) are found to be statistically insignificant. These results are consistent with the argument documented earlier; in the E-mini futures markets, the overnight session acts as a medium by means of which information is efficiently transferred from one daytime session to the next. Hence, the "24-hr-8:30AM-to- 8:30AM" return variances are not significantly different as compared to their "24-hr-3:15PM-to-3:15PM" counterparts. Our results provide further empirical support for the results and arguments in Amihud and Mendelson (1991), Dhillon et al. (1997) and Tse (1999). We conclude that despite the low trading volume, the overnight trading session aids in an efficient flow of information from one daytime trading session to the next, thereby mitigating the pricing errors in the process. Our results are in sharp contrast to those reported in studies pertaining to daytime markets, where daytime trading sessions are preceded by a long non-trading overnight period (e.g., Amihud and Mendelson 1987; Stoll and Whaley 1990).

\section{Conclusions}

In this study, we examine the potential information links between daytime and overnight trading sessions in the E-mini futures markets. We also examine if such a trading environment makes the E-mini markets any different as compared to those which operate only during regular trading hours (i.e., daytime markets in general). 
We find that for the sample period considered, daytime trades are more informative vis-à-vis the overnight trades, which is also the reason why, in accordance with the arguments documented in existing literature, the daytime trading returns are significantly more volatile as compared to their overnight counterparts. Higher volatility of daytime trading returns is a typical result for daytime markets in general. The trading volume patterns reveal that the daytime and overnight sessions are segmented and that the daytime E-mini traders behave as if they are operating in a daytime market. These results may be explained in light of the key finding documented in microstructure literature on E-minis; given the current trading environment at the CME, there is not much of an incentive for the E-mini traders to trade during the overnight session when the "floor is closed". The E-mini markets are therefore not 24-hour markets to the true sense of the word, and in particular, the daytime session behaves like a separate daytime market. This finding explains the higher variance of returns and the higher information share associated with the daytime trades. We also find that despite the low trading volume, the overnight session aids in an efficient flow of information from one daytime trading session to the next, thereby mitigating the pricing errors at the beginning of the daytime session. This result is in sharp contrast to those found in earlier studies on daytime markets.

The low trading volume for the overnight session should be a cause of concern for the CME authorities. Despite the fact that the E-mini futures markets are open for virtually 24-hours, results from this study highlight an acute lack of interest on the part of the E-mini traders to trade during the overnight session. Given the arguments in Grossman et al. (1980), there is always a risk that the low trading volume might become sufficiently low, so as to hinder an efficient flow of information from one daytime trading session to the next. We do see an opportunity here for the market regulators to try and boost the overnight trading volume, under the current infrastructural setup. Since the dynamics of the overnight session are considerably different as compared to its daytime counterpart, the CME might work towards getting the off-exchange customers to trade during the overnight session. Assuming that the off-exchange customers on an average trade a small number of contracts in any case, the volume/cost issue pointed out by Massimb and Phelps (1994) should not discourage them to trade during the overnight session.

Finally, Kurov et al. (2004) observe that, "Although most futures industry participants share the view that a permanent move from open outcry to electronic trading in most futures markets is all but inevitable, ...." If this becomes true some day, then the results of this study provide sufficient motivation to conduct this study again and examine the results. We believe the results will be quite interesting, if not radically different.

\section{References}

Admati, A. R., \& Pfleiderer, P. (1988). A theory of intraday patterns: Volume, price and Volatility. Review of Financial Studies, 1, 3-40. http://dx.doi.org/10.1093/rfs/1.1.3

Amihud, Y., \& Mendelson, H. (1987). Trading mechanisms and stock returns: An empirical investigation. Journal of Finance, 42, 533-553.

Amihud, Y., \& Mendelson, H. (1991). Volatility, efficiency and trading: Evidence from the Japanese stock market. Journal of Finance, 46, 1765-1790.

Ates, A., \& Wang, G. H. K. (2005). Information transmission in electronic versus open-outcry trading systems: An analysis of U.S. equity index futures markets. Journal of Futures Markets. 25, 679-715. http://dx.doi/org/10.1002/fut.20160

Baillie, R. T., Booth, G. G., Tse, Y., \& Zabotina, T.V. (2002). Price discovery and common factor models. Journal of Financial Markets, 5, 309-321. http://dx.doi.org/10.1016/S1386-4181(02)00027-7

Barclay, M.J., Litzenberger, R., \& Warner, J. B. (1990). Private information, trading volume and stock return variances. Review of Financial Studies, 3, 233-253. http://dx.doi.org/10.1093/rfs/3.2.233

Barclay, M. J., \& Hendershott, T. (2003). Price discovery and trading after hours. Review of Financial Studies, 16, 1041-1073. http://dx.doi.org/10.1093/rfs/hhg030

Brock, W.A., \& Kleidon, A. W. (1992). Periodic market closure and trading volume: A model of intraday bids and asks. Journal of Economic Dynamics and Control, 16, 451-489. http://dx.doi.org/10.1016/0165-1889(92)90045-G

Chung, H., Sheu, H., \& Hsu, S. (2010). Trading platform, market volatility and pricing efficiency in the floor-traded and E-mini index futures markets. International Review of Economics and Finance. 19(4), 742-754. http://dx.doi/org/10.1016/j.iref.2010.03.007

Coppejans, M., \& Domowitz, I. (1999). Pricing behavior in an off-hours computerized Market. Journal of Empirical Finance, 6, 583-607. http://dx.doi.org/10.1016/S0927-5398(99)00014-6 
Dhillon, U. S., Lasser, D. J., \& Watanabe, T. (1997). Volatility information and double versus Walrasian auction pricing in U.S. and Japanese futures markets. Journal of Banking and Finance, 21, 1045-1061. http://dx.doi.org/10.1016/S0378-4266(97)00012-5

Engle, R. F., \& Granger, C. W. J. (1987). Cointegration and error correction: Representation, estimation and testing. Econometrica, 55, 251-276. http://dx.doi.org/10.2307/1913236

French, K.R., \& Roll, R. (1986). Stock return variances: The arrival of information and the reaction of traders. Journal of Financial Economics, 17, 5-26. http://dx.doi.org/10.1016/0304-405X(86)90004-8

Grossman, S. J., \& Stiglitz. J. E. (1980). On the impossibility of informationally efficient markets. American Economic Review, 70, 393-408.

Harris, L. (1986). A transaction data study of weekly and intradaily patterns in stock Returns. Journal of Financial Economics, 16, 99-117. http://dx.doi.org/10.1016/0304-405X(86)90044-9

Hasbrouck, J. (1995). One security many markets: Determining the contributions to price Discovery. Journal of Finance, 50, 1175-1199.

Hasbrouck, J. (2003). Intraday price formation in U.S. equity index markets. Journal of Finance, 58, 2375-2400. http://dx.doi.org/10.1046/j.1540-6261.2003.00609.x

Johansen, S. (1988). Statistical analysis of cointegration vectors. Journal of Economic Dynamics and Control, 12, 231-254. http://dx.doi.org/10.1016/0165-1889(88)90041-3

Johansen, S. (1991). Estimation and hypothesis testing of cointegration vectors in Gaussian vector autoregressive models. Econometrica, 59, 1551-1580. http://dx.doi.org/10.2307/2938278

Kurov, A., \& Lasser, D.J. (2004). Price dynamics in the regular and E-mini futures Markets. Journal of Financial and Quantitative Analysis, 39, 365-384. http://dx.doi.org/10.1017/S0022109000003112

Kurov, A. (2008). Information and noise in financial markets: Evidence from the E-mini Index Futures. Journal of Financial Research, 31(3), 247-270. http://dx.doi.org/10.1111/j.1475-6803.2008.00239.x

Massimb, M. N., \& Phelps, B. D. (1994). Electronic trading, market structure and liquidity. Financial Analysts Journal, 49, 39-50. http://dx.doi.org/10.2469/faj.v50.n1.39

Oldfield, G. S., \& Rogalaski, R. J. (1980). A theory of common stock returns over trading and non-trading periods. Journal of Finance, 35, 729-751.

Ross, S. (1989). Information and volatility: The no-arbitrage martingale approach to timing and resolution irrelevancy. Journal of Finance, 44, 1-17.

Stoll, H.R., \& Whaley, R. E. (1990). Stock market structure and volatility. Review of Financial Studies, 3, 37-71. http://dx.doi.org/10.1093/rfs/3.1.37

Tse, Y. (1999). Round-the-clock market efficiency and home bias: Evidence from the international Japanese government bonds futures markets. Journal of Banking and Finance, 23, 1831-1860. http://dx.doi.org/10.1016/S0378-4266(99)00040-0

Tu, A. H., \& Wang, M. (2007). The innovations of e-mini contracts and futures price volatility components: The empirical investigation of S\&P500 Stock Index Futures. Journal of International Financial Markets, Institutions and Money. 17(2), 198-211. http://dx.doi/org/10.1016/j.intfin.2005.11.001

Werner, I. M., \& Kleidon, A. W. (1996). U.K. and U.S. trading of British cross-listed stocks: an intraday analysis of market integration. Review of Financial Studies, 9, 619-664. http://dx.doi.org/10.1093/rfs/9.2.619

Wood, R. A., McInish, T. H., Ord, J. K., \& Keith, J. (1985). An investigation of transaction data for NYSE stocks. Journal of Finance, 40, 723-741. 


\section{Notes}

Note 1. E-mini futures contracts are one-fifth the size of their regular counterparts. In other words, the contract multiplier for these contracts are one-fifth of those for the regular versions. For example, to determine the contract value of an S\&P 500 Futures contract, we need to multiply the S\&P500 index value by 250 (the contract multiplier). On the other hand, to determine the contract value of the corresponding E-mini version, we need to multiply the S\&P 500 index value by 50. Similarly, the contract multiplier for NASDAQ-100 Futures is 100 and the same for the corresponding E-mini version is 20 .

Note 2. Kurov et al. (2004) use the data from regular trading hours only, and they consider the time interval from 8:30AM

to 3:15PM as regular trading hours. This time interval coincides with open-outcry trading at the CME. Hence, as in Kurov et al. (2004), we also consider this time interval as "regular trading hours".

Note 3. At the NYSE, the opening price is determined by the market specialist by means of a market clearing procedure. Under this procedure, the traders either submit a limit order or a market order. These buy/sell orders accumulate and ultimately, the market clears at an opening price determined by the specialist. Once the opening price is determined by the clearing house mechanism, the continuous dealership market begins, and trading is carried out continuously by the market makers who quote the bid-ask prices. Amihud and Mendelson (1987).

Note 4. At the TSE, there are two clearing transactions: the first one initiates the morning trading session and the second one initiates the afternoon trading session.

Note 5. The E-mini futures markets never close, hence we use these terminologies instead of "open-to-open and close-to-close return variances" as has been used so far in the literature on regular markets.

Note 6. Several other E-mini futures contracts exist at the CME. Most of them have been introduced quite recently and do not have sufficient trading volume for a meaningful study. Apart from these two contracts considered here, we did however attempt to include E-mini Russell 2000 Futures (introduced on 8/24/01) and E-mini S\&P Midcap 400 Futures (introduced on 1/28/02) for this study. These two contracts were however dropped from further consideration because of the lack of trading volume and infrequent trading particularly in the overnight trading sessions.

Note 7. The unit root tests (ADF, Phillips-Peron and KPSS) and Johansen cointegration tests (Johansen 1988; Johansen 1991) are not reported here due to space constraints.

Note 8. In accordance with the discussion in Hasbrouck (1995), this error correction representation incorporates the fact that traders at 3:15PM react to the 8:30AM posted prices.

Note 9. The lag lengths for the VECM were chosen on the basis of AIC/SBC criteria.

Note 10. Kurov et at. (2004) follow the same approach.

Table 1. Summary Statistics of Average Intraday Trading Volumes

\begin{tabular}{|l|c|c|}
\hline & E-mini NASDAQ-100 & E-mini S\&P 500 \\
\hline & & 373 \\
\hline Minimum & 241 & 151,608 \\
\hline Maximum & 127,224 & $45,698.35$ \\
\hline Std. Dev & $37,876.48$ & 1.338 \\
\hline Skewness & 1.392 & 3.440 \\
\hline Kurtosis & 3.662 & 29,348 \\
\hline Avg. Hourly Volume & 23,824 & 94,439 \\
\hline Avg. Hourly Volume for the Daytime Session & 77,458 & 2,546 \\
\hline Avg. Hourly Volume for the Overnight Session & 1,739 & \\
\hline
\end{tabular}

Sample period is from September 1, 2004 through August 31, 2005. Average intra-day trading volumes are computed over a period of 259 trading days. The daytime trading session begins at 8:30AM and ends at 3:15PM. The overnight session begins at 3:15PM and ends at 8:29:59AM, the next day. The GLOBEX platform remains closed from 3:15PM thru 3:30PM, and from 4:30PM thru 5:00PM. Only the nearby contracts are used. If several trades occur at a particular point in time, only the last observation is used. 
Table 2. Summary Statistics of Daytime and Overnight Returns and $F$-tests

\begin{tabular}{|l|c|c|c|c|c|}
\hline Period & Skewnes & Kurtosis & Mean & Variance & $F$-statistic \\
\hline Panel A: E-mini NASDAQ-100 Futures & & & & & \\
\hline Daytime Returns & -0.044 & 3.162 & -0.008 & 0.685 & $4.28^{* *}$ \\
\hline Overnight Returns & 0.880 & 6.893 & 0.071 & 0.160 & \\
\hline & & & & & \\
\hline Panel B: E-mini S\&P 500 Futures & & & & & \\
\hline Daytime Returns & -0.315 & 3.980 & 0.015 & 0.578 & $2.10^{* *}$ \\
\hline Overnight Returns & 0.272 & 3.310 & 0.026 & 0.275 & 2.26 \\
\hline
\end{tabular}

** indicates significance at the $5 \%$ level.

The variance is estimated for the entire sample. The estimation period is 259 trading days; September 1, 2004 through August 31, 2005. The $F$-Statistic tests for equality of variance for the daytime and overnight returns respectively. The 8:30 AM and 3:15PM prices are used to compute the daytime trading returns. The 3:15PM and 8:30AM prices, for the next day, are used to compute the overnight returns.

Table 3. Information Share Statistics for Daytime and Overnight Trades

\begin{tabular}{|l|l|l|}
\hline & Daytime & Overnight \\
\hline Panel A: E-mini NASDAQ-100 Futures & \\
\hline Upper Bound & $99.39 \%$ & $0.62 \%$ \\
\hline Lower Bound & $99.38 \%$ & $0.61 \%$ \\
\hline Midpoint & $99.38 \%$ & $0.61 \%$ \\
\hline Panel B: E-mini S\&P 500 Futures & $67.32 \%$ & \\
\hline Upper Bound & $66.52 \%$ & $33.48 \%$ \\
\hline Lower Bound & $66.92 \%$ & $32.68 \%$ \\
\hline Midpoint & & $33.08 \%$ \\
\hline
\end{tabular}

Statistics are based on a VECM of two price series; E-mini futures prices from the daytime trading session and the same from the overnight trading session. If several trades occur at a particular point in time, only the last observation is used. Sample period is 259 trading days; September 1, 2004 through August 31, 2005. The daytime trading session being shorter in duration as compared to its overnight counterpart, the corresponding price series are spaced at 5-minute and 12-minute intervals respectively. The cointegration tests are not reported. According to the Hasbrouck (1995) information share model, the information share of a price series is defined as the proportion of the efficient price innovation variance that may be attributed to that price series. The figures under the columns "Daytime" and "Overnight" are the information shares. "Midpoint" refers to the mean information shares respectively.

Table 4. Summary Statistics of 24-hr-8:30AM-to-8:30AM Returns and 24-hr 3:15PM-to-3:15PM

\begin{tabular}{|l|l|l|l|l|l|}
\hline Period & Skewnes & Kurtos is & Mean & Variance & $F$-statistic \\
\hline Panel A: E-mini NASDAQ-100 Futures & & & & & \\
\hline 24hr. 8:30:00AM-to-8:30:00AM Returns & -0.106 & 3.838 & 0.059 & 0.743 & 1.06 \\
\hline 24hr. 3:15:00PM-to-3:15:00PM Returns & 0.157 & 3.694 & 0.059 & 0.785 & \\
\hline & & & & & \\
\hline Panel B: E-mini S\&P 500 Futures & & & & & \\
\hline 24hr. 8:30:00AM-to-8:30:00AM Returns & -0.276 & 3.583 & 0.039 & 0.354 & 1.16 \\
\hline 24hr. 3:15:00PM-to-3:15:00PM Returns & -0.061 & 2.987 & 0.039 & 0.413 & \\
\hline
\end{tabular}

The variance is estimated for the entire sample. The estimation period is 259 trading days; September 1, 2004 through August 31 , 2005. The $F$-Statistic tests for equality of variance for the "24-hr-8:30AM -to-8:30AM Returns" and "24-hr-3:15PM -to-3:15PM Returns" respectively. 


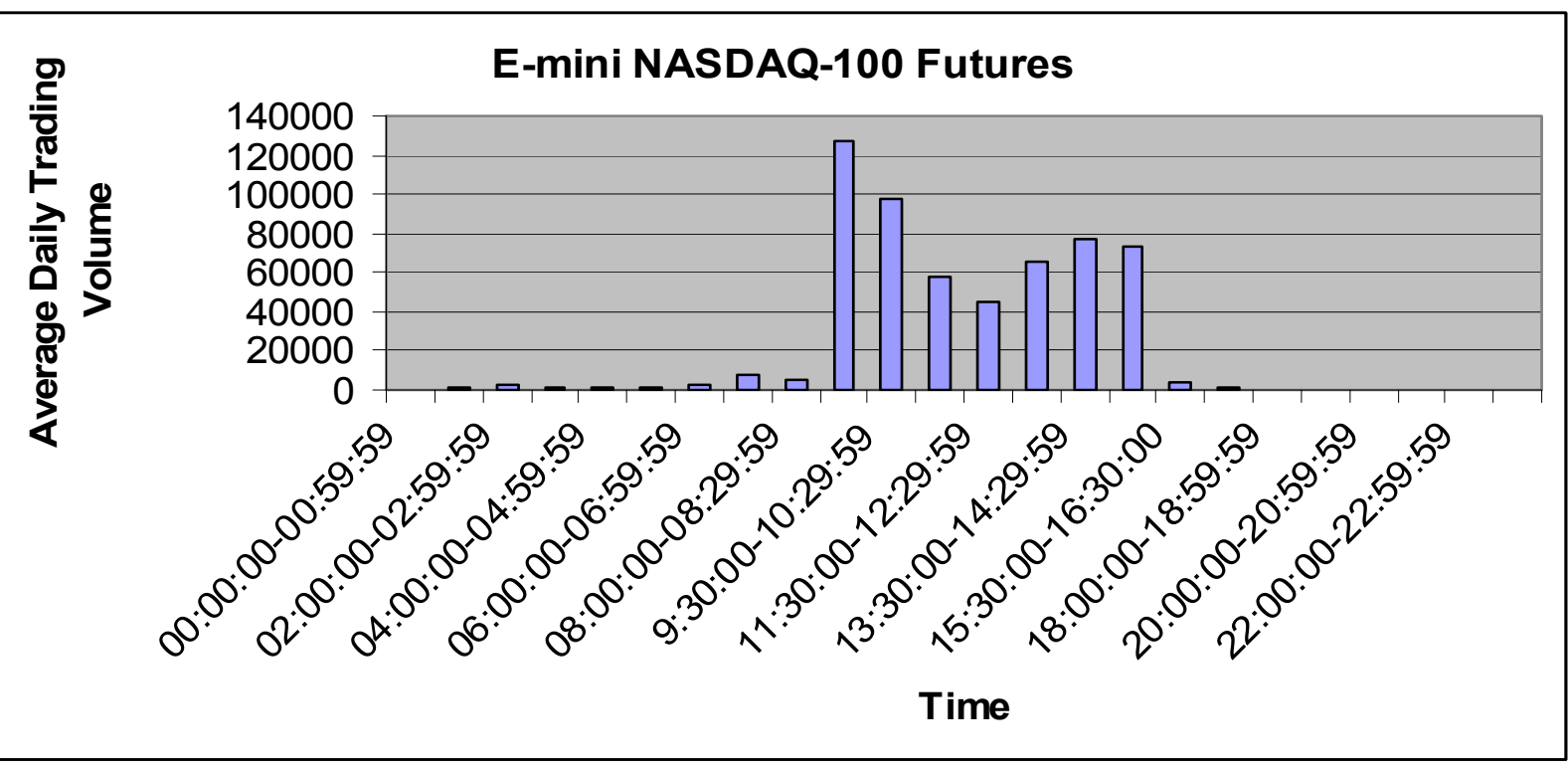

Figure 1(a)

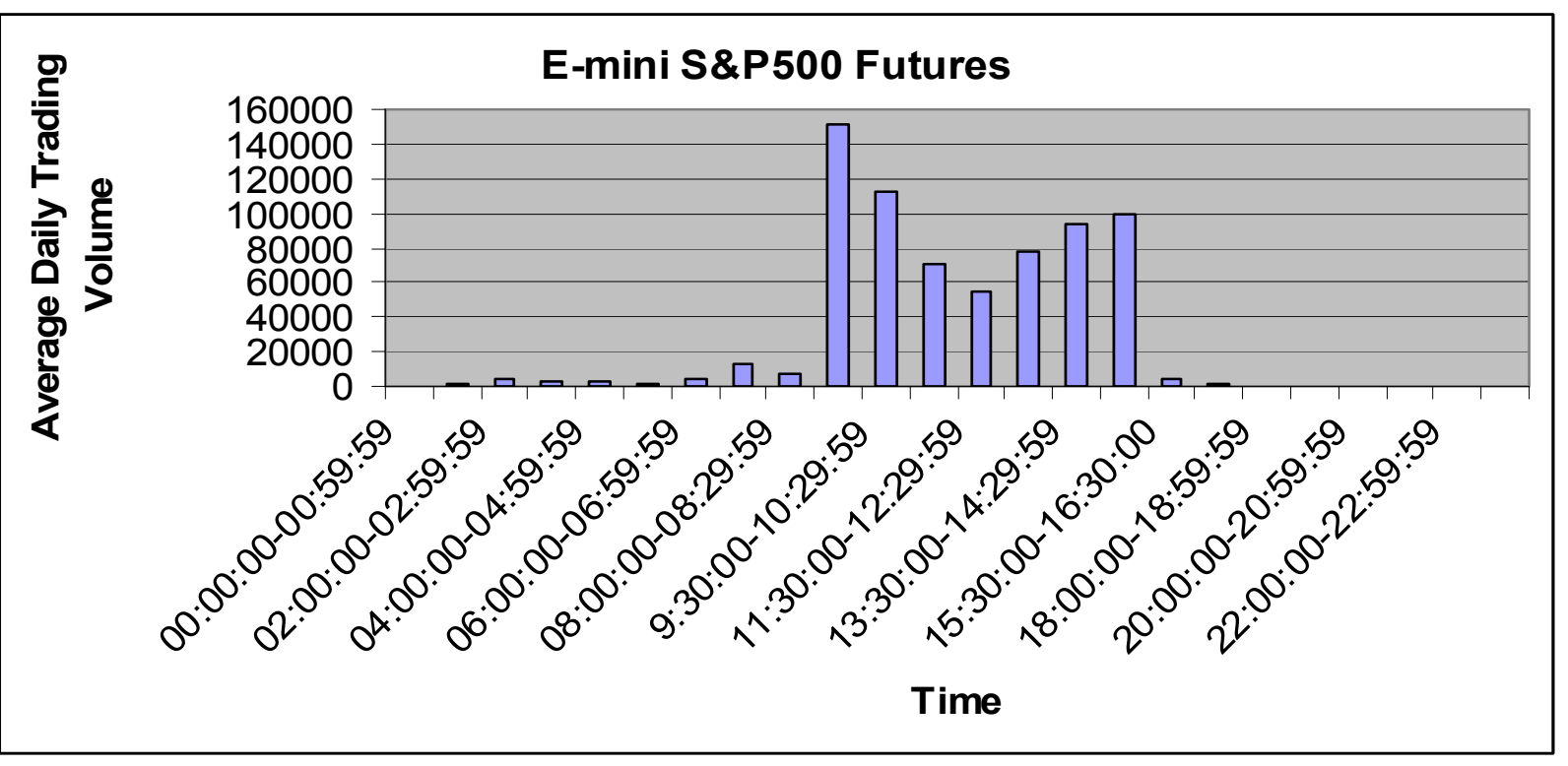

Figure 1(b)

Figure 1. The average hourly volumes are obtained over a sample period of 259 trading days; September 1, 2004 through August 31, 2005.

Alternate intervals are labeled. 